\title{
DISTINCTIVE FEATURES OF ORGANIZATION OF PRODUCTION AT LIGHT INDUSTRY ENTERPRISES
}

\author{
Tursunov Bobir Ortikmirzaevich
}

Received: October 13, 2017 | Accepted: May 16, 2018

\begin{abstract}
Consumer market conjuncture traditions remain a high demand for finished products. The immediate tasks of marketing staff and managers of manufacturers of finished products should be rapid response to market conditions, ie to fully meet consumers' demand for competitive finished products by utilizing available equipment and workforce resources at the workplace. That is why our article also highlights the peculiarities of productivity and organization. We have the courage to express our thoughts on this subject. At the moment, the main task is to increase the production volume, to improve the quality of products, to improve their technical level, to meet the demand for consumer goods. For this purpose, it is necessary to improve production management structure, to organize and develop production, to use all the resources of the working time, labor and production. The issue of efficiency and efficiency of production in the economy has always been a pressing problem. Especially in the conditions of strong competition, this issue is getting tougher. It is impossible to survive the competition without increasing production efficiency.
\end{abstract}

Keywords: productivity, light industry, production, materials, specialization.

\section{INTRODUCTION}

The main problem of the research is the study of the role of regional light industry in the development of the country's economy and the efficient use of available resources in the region.

As a result of the research, it is planned to define the directions of development of the light industry enterprises, to develop the basics of the product sales, and to develop the perspectives of the establishment of enterprises in the specific regions.

\footnotetext{
Tashkent State University of Economics, Tashkent city, the Republic of Uzbekistan;
}

Contact: tursunov-bobir@mail.ru 


\section{LITERATURE REVIEW}

Other scientists, such as Casey J. Dawkins, Petr Hlavachek, Petra Olsova and Roberta Capello, studied the problems of the theory of development of economic sectors, factors of raising the effectiveness of regional enterprises on the example of the country or its regions.

The organizational-legal and theoretical-methodological foundations of the implementation and consistent continuation of economic reforms in Uzbekistan, the territorial development of the country's economy, as well as the modernization and diversification of sectors of the economy, particularly industrial sectors, are widely covered in the fundamental works and speeches of the first President I.Karimov.

Uzbekistan has been consistently carrying out research on the peculiarities of radical renewal of the economy of the real sector, in particular the light industry, and raising competitiveness. Khasanov, X. Asatullaev, A. Suvonkulov, X. Hakimov, M. Amonboev, Sh.X. Toshmatov, G. Zahidov, Z. Khakimov and others.

\section{MAIN PART}

Successful achievement of successive and comprehensive measures, important tasks and directions, development and clear definition of various levels of economic development programs in the provision of consistent and sustainable development of the economy for the coming period. At the same time, it is important to make conclusions by critically evaluating the achievements and results achieved in the previous period and further improving the socio-economic development programs on their basis. Efficiency of production enterprises is determined by the level of technical base growth and organization of production process and product creation. The main activity of the enterprises is the process of production.

Its main task is to create value. The production process involves a complex process, involving interconnected technological and labor processes. Technological process this is the result of the change of work products and includes natural processes. In this case, live labor does not participate, but this process is carried out at a moderate level.

The study process is focused on the consumption of physical and mental energy. The results of the manufacturing process depend on the technological regime and the totality of conditions (the total technological requirements for the process: the composition of raw materials and materials, moderate pressure, and other production factors).

Existing production facilities and production facilities (production premises, lighting equipment, warehouses, etc.) are used in modern enterprises to carry out the production process. If these conditions are not present, the process can either be absolutely inaccurate or just unfinished.

The production process is subdivided into basic, auxiliary and serving processes, depending on the role of light industry in its production. The main process is the conversion of working materials to the main product. 
It provides auxiliary processes for the production and ensures uninterrupted operation of the product manufacturing process. These include: supply of production equipment (stamps, models, repair and maintenance, repair and maintenance), repair (maintenance, modernization and maintenance of various equipment), various energy (electricity, steam, and so on).

Service delivery includes logistical support of enterprises, sale of finished products, transportation services and so forth.

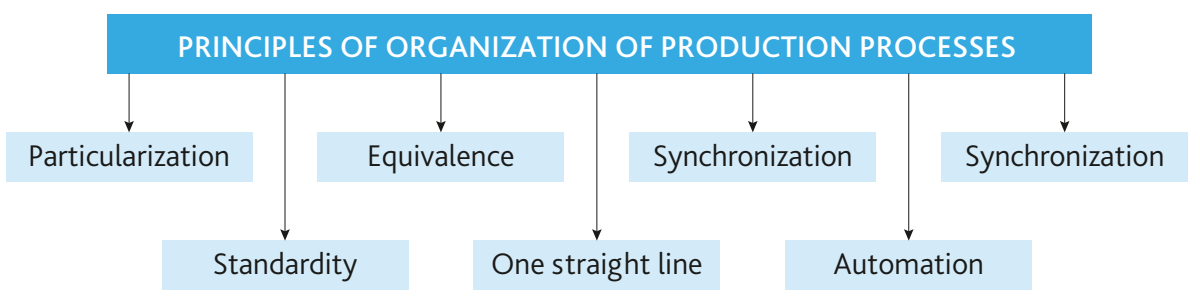

Figure 1. The principles of organization of production processes

Source: Made by author

The production processes are divided into continuous, continuous, and continuously depending on the nature of the time. In recycling processes, raw materials and materials are continuously processed using equipment and thus converted to finished product. Any light industry enterprises are rationalized on the basis of the process of organization of production on the basis of live working items and labor. This implies high productivity in the use of equipment, raw materials, materials, fuel, electricity and other means of production and labor. Rational organization of production ensures proportionate improvement of production (Figure 1).

The essence of these principles is as follows:

Specialization principle. Specialization is a form of social division of labor, which is systematically developing in the industrial sector and implies separation of industries, enterprises, workplaces, lines and certain jobs.

The principle of proportionality. The proportion of production processes indicates that the working capacity of all production units (main and auxiliary workshops, sections and lines inside the workshops, equipment group and workplace) coincides with each other in proportion to each other. If these principles are not observed, there will be disproportionate and «narrow places», which, in turn, will hamper the production growth in enterprises. The principle of proportionality, based on the complex mechanization and automation of industrial enterprises.

The principle of parallelism. The essence of this principle is to simultaneously handle several parts of the manufacturing process, ie the work on the preparation of products is widespread.

When applying the principle of a serial, straight line, the production process helps to identify the work items in the shortest possible way from all stages of production process (from the raw materials and supplies to the release of the finished product and to the consumer up to In order to achieve a straightforward, straightforward direction, the 
equipment and equipment should be placed in a reasonable location, and in addition to preventing the movement and return of raw materials and materials on the basis of proper placement of the main and auxiliary shops within the plant.

The principle of discontinuity means uninterrupted operation during production, no break, that is, continuous operation.

The principle of proportionality is defined by the fact that the production units are interconnected with the completion of the same volume of work according to the work program at the same interval.

The principle of automation. This principle requires maximum automated operation of production processes, that is, direct participation or under supervision of workers. High level automation of some operations of the production process is the basic prerequisite for complex automation of production, which should be carried out before the creation of automated system lines. This principle is widely used not only in technological processes, but also in their technical preparation, control, regulation, and maintenance.

Synchronization principle. Synchronization of production process is characteristic of continuous production and automatic generation. Synchronization of the production process is understood as:

- Equal time spent on operations (operational time);

- Equality of time spent for work and linear transport of labor;

- Equality of breaks in operational work on workplace rest and workplace rest;

- When the operations are completed during the systemic movement of the workpiece, the timing of the start of their transport is commensurate.

Even if one of these four conditions is not met, the production process does not synchronize too much.

The most advanced forms of production organization include specialization, cooperation and combining. Manufacturing specialization is one of the most important forms of social division of labor, which is closely linked to the scientific and technical development and production management system. The basis for the inter-company and division of labor between them is the specialization of labor armament. Specialized inbuilding specialization will be directed at the production of sections and sections for the production of certain products or a certain stage of the technological process.

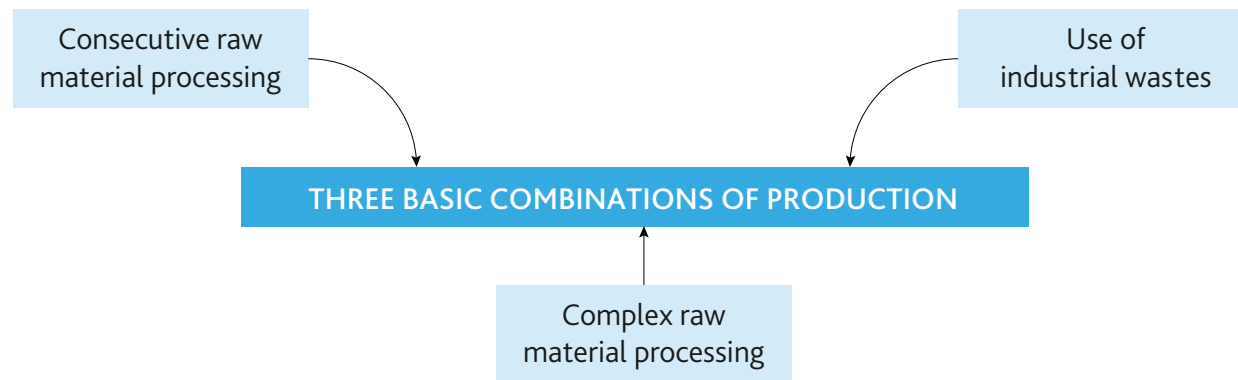

Figure 2. Combining form in production

Source: Made by author 
Specialization is based on standardization, standardization and unification of details, as well as technological processes are mechanized and widely used by specialized equipment. The level of specialization of enterprises and their divisions depends largely on two factors: production volumes and product demand.

There are three types of specialization in light industry enterprises: specialization in materials, technological, details. As a result of technological specialization of workshops, sites and workplaces, each of them performs the same technological process and the same. For example, spinning, weaving and others in textile factories are examples of technological specialization.

According to the possibilities of specialization cooperatives are divided into three types:

- Cooperative work on the goods, whereby some shops will be able to supply assembly units ready for assembly;

- Cooperative detail, detailing the details of the workshop;

- In a technological cooperative, a workshop supplies semi-finished products for the other, or performs special operations.

Combination with specialization and cooperatives is also one of the main forms of organization of production at enterprises.

The combination can be summarized as follows: Combination is a meeting of various sectors of the industry into one enterprise, where these sectors are sectors that are serial or raw materials for the raw materials (for example, utilizing items that are in use or waste, production, etc.).

The availability of the equipment varies when the range of production and specialization levels vary. The volume of the same product is influenced by the choice of equipment and the chemical properties of the technological equipment. The high-end equipment that is designed for the preparation of some items is not suitable for the different and frequently changing plants. They identify the structure of production and the specific process of the technological process and their armament, the processes of production and the forms of work organization and specific methods of management.

\section{CONCLUSION}

An important factor in the development of light industry is the efficient organization of production. Therefore, it is desirable for us to do more effectively for our production capacity:

- Renting premises and premises of non-operating enterprises on sub-contracted basis to other enterprises;

- Implementation of energy efficient and water-efficient technologies based on production, with a view to reducing the cost of manufactured products;

- Constant monitoring of the location of workers and their rotation;

- Use Kaizen principles to ensure the quality of products manufactured by the industry; 
- Reduce the production cycle duration.

In sum, it is desirable to put forward the above suggestions in the future in order to increase the competitiveness of light industry enterprises, reduce product cost and make full use of production capacities.

\section{REFERENCES}

Abdukarimov, I.T. (2010) etc. Analysis of enterprise economic potential. - T .: Economic and legal world, 256p.

Belyx, L.P. (2010) Restructuring Predmeters. Book.- M .: UNITI-DANA, 356p.

Casey, J. Dawkins, R. (2009) Development Theory: Conceptual Foundations, Classic Works and Recent Developments, 219p.

Khasanov R., and others. (2013) Rela sector economy and its forecasting. Educational manual. Ministry of Higher and Secondary Special Education of the Republic of Uzbekistan. TMI. T .: «ECONOMIC FINANCE», $192 \mathrm{~b}$.

Prosvetov, G.I. (2010) Strategy prediction. Ucheb. prakticheskoe posobie - M .: AlfaPress, $184 \mathrm{p}$.

Petr Hlavachek, Petra Olsova. (2014). Regional Economy and Policy, 187p.

Roberta Capello. (2008) Regional Economics, Second Edition. 586p.

Shogiyokov, T.Sh. (2009) Comprehensive Economic Analysis T : «ECONOMIC FINANCE», 224p.

Vahobov et al. (2011) Financial and Management Analysis: Textbook. - T .: «Sharq», 480 p. Yusupov, M., and others. (2015) «Economy of the real sector» - Educational aid - T .: $300 \mathrm{p}$.

Zakhidov G. (2014) Prospects of development of light industry in Uzbekistan, 164p. 